\section{Islam: governments need to reform education and build a scientific culture}

SIR - We read with interest your recent "Islam and science" issue focused on science in the Muslim and Arab world (Nature 444, 1, 19-29 and 33-36; 2006). It addresses many of the barriers to the advancement of science in the Muslim world.

As scientists from the region - we both come from Yemen - we would like to stress that the biggest impediment to the progress of science in the Arab/Muslim world is not Islam but the absence of a scientific research culture and of national research strategies, combined with the failure of the educational systems, particularly higher education. The greatest contributions to science occurred during an era when Islam dominated the civilized world.

Research and education are inseparable: you cannot have one without the other. Higher-education institutions and centres of excellence are the driving engines of the economic growth and competitiveness of the knowledge-based economies in the West. The number of research-based $\mathrm{PhD}$ programmes is limited or non-existent in many Muslim/Arab countries.

At the core of the problem in the Muslim/ Arab world is the existence of, primarily, two forms of educational institution: government and for-profit private institutions. Neither system is compatible with the development of a world-standard scientific infrastructure.

The government institutions have funding, but no financial independence or control of their resources. Their faculty members and administrators are appointed on political grounds, not on merit. So whether the country is rich like Saudi Arabia or poor like Yemen, the result is the same: substandard education and research.

On the other hand, the number of private universities in the Arab world is rising. However, almost all are profit-driven and generally focus on small programmes that require little infrastructure.

This situation contrasts significantly to that in the West, where universities are non-profit, self-governing institutions, and governments provide partial funding but do not dictate how the money is spent.

In your Editorial "Science and the Islamists" (Nature 444, 1; 2006) you correctly indicate the need for rulers to foster and seek inspiration. The terrible conflicts continuing in most Muslim countries are affecting millions of people's basic everyday needs. Clearly, this has deterred the advancement of science in those countries and left contributions in science to other nations.

However, let us distinguish clearly between Islam's position on science and current practices.

The first instruction revealed to the prophet Muhammad was to read, think and ponder about God's creation. The Koran and the record of the prophet's practices (the sunnah and hadiths) are full of scientific concepts that inspired Muslims in the past to contribute to humanity and civilization.

The world has lost a lot because of the current state of affairs in Muslim countries. One would hope that, if the past predicts the future, then under good Islamic rule science will prevail again. Muslim scientists will then once again make pioneering contributions to science and to many other aspects of life.

In order to advance science and build knowledge-based economies, Arab and Muslim countries must:

- create a scientific culture that recognizes the contribution of scientists and values higher education and research;

- build state-of-the-art research facilities as centres of excellence; - set up merit-based structures that foster academic freedom and promote independent scholarship;

- adopt policies that facilitate the flow of information and exchange of research materials between scientists and their counterparts around the world;

- take active approaches to reverse the brain drain of Muslim and Arab scientists and attract talent to the region, irrespective of religion, nationality or ideology;

- separate politics from scientific education.

Advancing science and building knowledge-based economies in the region will require concerted and systematic efforts by leading Muslim academics, intellectuals and policy-makers. Lessons could be learnt from the recent success stories of Asian countries such as China, South Korea and Singapore.

As directors of our respective laboratories, we are among the many Arab/Muslim scientists who have left the region and are now well-established abroad. Few are likely to abandon their position and return home at present, because the conditions that attracted them abroad do not exist in the region. In this respect, not only has the Arab/Muslim world failed to produce and retain scientists, it has also failed to capitalize on the large resources of successful and accomplished expatriate Muslim scientists.

Until the situation changes, Arab/Muslim countries should reach out and develop efficient mechanisms for mobilizing expatriate scientists and utilizing their knowledge, expertise and resources for their home countries' development. Hilal A. Lashuel ${ }^{\star}$, Nasser Zawia'

* Laboratory of Molecular Neurobiology and Neuroproteomics, Brain Mind Institute, Ecole Polytechnique Fédérale de Lausanne (EPFL), $\mathrm{CH}-1015$ Lausanne, Switzerland $\uparrow$ Neurotoxicology and Epigenomics Laboratory, Department of Biomedical and Pharmaceutical Sciences, University of Rhode Island, Kingston, Rhode Island 02881, USA

\section{Islam: science is held back by paternalistic traditions}

SIR - The News Feature "An Islamist revolution" (Nature 444, 22-25; 2006) and other articles in Nature's "Islam and science" special issue make interesting reading. As a former executive director of the Pakistan Medical Research Council, I note that the current lack of capacity for science in Islamic countries is well highlighted, and the great uncertainty in predicting its future (despite some recent positive developments) is rightly underscored.

Islamic countries do not currently have the right environment or culture for science. They lack all the critical ingredients required: policies, institutions, critical mass of productive and vocal scientists and an aware and appreciative population. Despite some lip-service being paid, science and research are not valued. Therefore, it is debatable whether the form of government - secular or Islamist - is going to make much difference to the current situation in these countries.

Your News Feature rightly points out that Islam is interpreted differently in different countries and even in different parts of the same country. Therefore, religion cannot be the reason for the current science deficit - and a look at the history of Islamic-era science will support this view.

Paternalistic cultures in the Islamic countries can more reasonably be blamed. Under these cultures, inquiry and freedom of expression are actively discouraged in the home, at school, at work and in response to government policies. The capacity for critical analysis is a fundamental requirement for science, but where it has no chance of developing under lifelong suppression, how can science and research be expected to flourish? Money alone cannot address the problem: a more fundamental change in thinking and behaviour is needed. Tasleem Akhtar

Fatima Memorial System, Shadman, Lahore 5400, Pakistan

Readers are encouraged to add their comments to the Islam and Science commentary on Nature's News Blog at: http://blogs.nature.com/news/ blog/2006/11/islam_and_science.html 